\title{
Two-dimensional CFD simulation and pilot-scale experimental verification of a downdraft gasifier: effect of reactor aspect ratios on temperature and syngas composition during gasification
}

\author{
Chootrakul Siripaiboon $^{1} \cdot$ Prysathyrd Sarabhorn $^{1} \cdot$ Chinnathan Areeprasert $^{1}$ (D)
}

Received: 29 February 2020/Revised: 18 June 2020/Accepted: 28 July 2020/Published online: 16 August 2020

(C) The Author(s) 2020

\begin{abstract}
This paper focuses on a two-dimensional CFD simulation of a downdraft gasifier and a pilot-scale experiment for verification using wood pellet fuel. The simulation work was carried out via the ANSYS-Fluent CFD software package with in-house coding via User Defined Function. Three gasification parameters were taken into account in the simulation and validation to achieve highly accurate results; namely, fuel consumption, temperature profile, and syngas composition. After verification of the developed model, the effects of aspect ratios on temperature and syngas composition were investigated. Results from simulation and experimental work indicated that the fuel consumption rate during the steady state gasification experiment was $1.750 \pm 0.048 \mathrm{~g} / \mathrm{s}$. The average steady state temperature of the experiment was $1240.32 \pm 14.20 \mathrm{~K}$. In sum, the fuel consumption and temperature profile during gasification from modeling and experimentation show an error lower than $1.3 \%$. Concentrations of $\mathrm{CO}, \mathrm{CO}_{2}, \mathrm{H}_{2}$, and $\mathrm{CH}_{4}$ were $20.42 \mathrm{vol} \%, 15.09 \mathrm{vol} \%$, $8.02 \mathrm{vol} \%$, and $2.6 \mathrm{vol} \%$, respectively, which are comparable to those of the experiment: $20.00 \mathrm{vol} \%, 15.48 \mathrm{vol} \%$, $8.00 \mathrm{vol} \%$, and $2.65 \mathrm{vol} \%$. A high concentration of syngas is observed in the outer radial part of the reactor because of the resistive flow of the air inlet and the synthesis gas produced. The average temperatures during the steady state of the gasifier with aspect ratios $(H / D)$ of $1.00,1.38$ (experiment), and 1.82 were $978.77 \pm 11.60,1256.46 \pm 9.90$, and $1368.94 \pm 9.20 \mathrm{~K}$, respectively. The 1.82 aspect ratio reactor has the smallest diameter, therefore the radiative heat transferred from the reactor wall affects the temperature in the reactor. Syngas compositions are comparable. Inverse relationships between the aspect ratios and the syngas LHV, $\left(4.29-4.49 \mathrm{MJ} / \mathrm{N} \mathrm{m}^{3}\right)$, cold gas efficiency $(29.66 \%$ to $31.00 \%$ ), and carbon conversion (79.59\% to $80.87 \%$ ) are observed.
\end{abstract}

Keywords CFD · Simulation · Gasification · Downdraft gasifier · Biomass · Wood pellets · Aspect ratio

List of symbols

$G_{\mathrm{k}} \quad$ Kinetic energy due to the mean velocity gradients

$G_{\mathrm{b}} \quad$ Turbulence kinetic energy due to buoyancy

$Y_{\mathrm{M}} \quad$ Fluctuating dilatation in compressible turbulence

$C_{1 \varepsilon}, C_{2 \varepsilon}, C_{3 \varepsilon} \quad$ Constant

Chinnathan Areeprasert

fengcta@ku.ac.th

1 Department of Mechanical Engineering, Faculty of Engineering, Kasetsart University, 50 Ngam Wong Wan Road, Lat Yao, Chatuchak, Bangkok 10900, Thailand $\sigma_{k}$

$\sigma_{\varepsilon}$

$S_{k}$

$S_{\varepsilon}$

$S_{i}$

$|v|$

D, C

$h$

$\Delta H$

$h_{\text {ref }}$

$T_{\text {ref }}$

$c_{\mathrm{p}}$

$R_{i}$
Turbulent Prandtl number for $k$

Turbulent Prandtl number for $\varepsilon$

User-defined source terms for $k$

User-defined source terms for $\varepsilon$

Source term for the $i$ th $(x, y, z)$ momentum equation

Magnitude of the velocity

Prescribed matrices

Sensible enthalpy

Latent heat enthalpy

Reference enthalpy

Reference temperature

Specific heat at constant pressure

Net rate of production of species $i$ 


$\begin{array}{ll}S_{\mathrm{c}} & \text { Rate of creation } \\ \theta_{\mathrm{R}} & \text { Radiation temperature } \\ m_{\mathrm{p}, 0} & \text { Initial particle mass } \\ D_{\mathrm{i}, \mathrm{m}} & \text { Diffusion coefficient for oxidant in the bulk } \\ \rho_{\mathrm{g}} & \text { Gas density } \\ \mu & \text { Molecular viscosity of the fluid } \\ M_{\mathrm{w}, \mathrm{i}} & \text { Molecular weight of species } \\ R_{\mathrm{i}, \mathrm{r}} & \text { Arrhenius molar rate of creation/destruction } \\ Y_{\mathrm{p}} & \text { Mass fraction of a product species } \\ Y_{\Re} & \text { Mass fraction of a particular reactant } \\ A & \text { Empirical constant equal to } 4.0 \\ B & \text { Empirical constant equal to } 0.5 \\ u & \text { Fluid phase velocity } \\ u_{\mathrm{p}} & \text { Particle velocity } \\ \rho & \text { Fluid density } \\ \rho_{\mathrm{p}} & \text { Density of the particle } \\ F_{x} & \text { Additional acceleration force per unit of } \\ F_{\mathrm{D}} & \text { particle mass } \\ m_{\mathrm{p}} & \text { Drag force } \\ c_{\mathrm{par}} & \text { Mass of particle } \\ A_{\mathrm{p}} & \text { Heat capacity of the particle } \\ T_{\infty} & \text { Surface area of the particle } \\ h_{\mathrm{c}} & \text { Local temperature of the continuous phase } \\ \varepsilon_{\mathrm{p}} & \text { Convective heat transfer coefficient } \\ \sigma & \text { Particle emissivity } \\ f_{\mathrm{v}, 0} & \text { Stefan-Boltzmann constant } \\ A_{0} & \text { Fraction of volatiles initially present in the } \\ Y_{O X} & \text { particle } \\ S_{\mathrm{b}} & \text { Rate constant } \\ d_{\mathrm{p}} & \text { Local mass fraction of oxidant in the gas } \\ & \text { Stoichiometry of the equation } \\ & \text { Particle diameter } \\ & \end{array}$

\section{Introduction}

Biomass comprises waste materials from plants or animals that store chemical energy in the form of carbon (Basu 2013; Klass 1998). Many technologies have been developed to exploit energy from biomass such as combustion, gasification, and pyrolysis (Bahng et al. 2009). Conventional combustion of biomass converts biomass to heat by direct burning or co-firing with coal (Savolainen 2003; Werther et al. 2000). Pyrolysis converts biomass into biooil products that can be used for energy and biofuel applications (Jahirul et al. 2012; Kan et al. 2016). Gasification produces synthesis gas or "syngas" from biomass through a series of chemical reactions (Susastriawan and Saptoadi 2017). It is a partial oxidation process and the main components of syngas are carbon monoxide $(\mathrm{CO})$, hydrogen $\left(\mathrm{H}_{2}\right)$, carbon dioxide $\left(\mathrm{CO}_{2}\right)$, and methane $\left(\mathrm{CH}_{4}\right)$ (Sikarwar et al. 2016). Syngas from the gasification process can be used in many applications including electrification, heat generation, and chemical production (Dasappa et al. 2003; Klass 1998; Ruiz et al. 2013).

Gasification reactors or gasifiers are equipment used to convert solid fuel, including biomass material, into gaseous fuel (Mahinpey and Gomez 2016). There are three main types of gasifier, namely a fixed-bed gasifier, a fluidizedbed gasifier, and an entrained flow gasifier. For large-scale coal-firing, fluidized-bed and entrained flow gasifiers are utilized (Mahinpey and Gomez 2016; Ruiz et al. 2013). For fixed-bed gasifiers, two well-known configurations, differentiated by the relative motion of the feedstock and gasifying agent, are the downdraft (co-current flow) and updraft (counter-current flow) models (Warnecke 2000). In general, fixed-bed gasifiers are utilized for small- to medium-scale heat and power generation applications (Chopra and Jain 2007; Hasler and Nussbaumer 1999; Susastriawan and Saptoadi 2017).

Modeling of biomass gasification can be categorized into four groups: kinetics, thermodynamic equilibrium, computational fluid dynamics (CFD), and artificial neural networks (ANN) (Basu 2013). The first two modeling methods do not deliver sufficiently accurate results and they cannot clearly explain the phenomena occurring during the gasification process (Antonopoulos et al. 2012). Conversely, ANN can tackle complex nonlinear functions and gives a good prediction outcome. However, it takes a long time, requires considerable processing resources, and is expensive (Baruah et al. 2017). As such, CFD is widely preferred in both scientific fields and engineering applications (Liu et al. 2013). Due to the fixed-bed gasifier's simplicity, CFD is sufficient for gasification process simulation and prediction. An updraft biomass gasifier was studied by two-dimensional CFD (2D CFD) modeling to optimize air flow rate for $\mathrm{CO}$ production (Fernando and Narayana 2016). The simulation for the lab-scale updraft gasification experiment showed that a flow rate of $7 \mathrm{~m}^{3} / \mathrm{h}$ maximized CO yield. Wu et al. (2013) used ANSYS Fluent software in a 2D CFD study of highly preheated air and steam biomass gasification in a demonstration-scale fixedbed downdraft gasifier employing the Euler-Euler multiphase approach with chemical reactions. Increase of the steam to air ratio helped to diminish tar content as well as increase $\mathrm{H}_{2}$ and $\mathrm{CO}_{2}$ content and the simulation results agreed with the experimental data. CFD using the EulerLagrange approach for dispersed two-phase flows was utilized for $10 \mathrm{~kg} / \mathrm{h}$ downdraft gasifier modeling; the simulation and experiment found that the air flow rate affected the temperature profile along the height of the gasifier as well as the concentration of the composition of the syngas 
outlet (Meenaroch et al. 2015). Simulation of a 40-kW downdraft gasifier using rice husks as fuel was performed by Murugan and Sekhar (2017). Results predicted that the equivalence ratio (ER) of the gasification process of 0.30 gave maximum syngas heating value of $5.19 \mathrm{MJ} / \mathrm{N} \mathrm{m}^{3}-$ the syngas composition was $22 \% \mathrm{CO}, 13 \% \mathrm{H}_{2}, 8 \% \mathrm{CO}_{2}$, and $1.7 \% \mathrm{CH}_{4}$. Most downdraft gasification CFD simulations address temperature distribution and syngas composition as the two main parameters for verification. Another important parameter, i.e. fuel consumption or mass loss rate of the feedstock, has not been considered because generally it has been presumed as a steady state process. However, to realize the effect of physical mass degradation during the transient period, this study incorporated mass loss rate results into the CFD model. Therefore, the three gasification parameters were taken into account in the simulation and validation procedures to achieve highly accurate results and both simulation and experimental works covered the gasification process from the transient to the steady state.

This work presents two-dimensional CFD modeling of a downdraft gasifier and a pilot-scale experiment using wood pellet fuel for verification. The ANSYS-Fluent CFD software package was utilized with in-house coding via a User Defined Function (UDF) written in C code. The purpose of this study was to develop a model for a fixed-bed downdraft gasifier which has proved to be stable, practical equipment for small-scale applications such as electrification and thermal generation in rural areas. Three main parameters were used in the verification process, namely, fuel consumption, temperature profile, and syngas composition. The simulation and experiment investigated the gasification process from the transient to the steady state. After the developed model was verified, the effects of aspect ratios on temperature and syngas composition were investigated. The results can be used in designing smallscale downdraft gasifiers for rural area application.

\section{Materials and methods}

\subsection{Computational method}

The downdraft gasifier model had two main design components: (1) air flow into the reactor and (2) combustion/gasification inside the reactor. Air flowed into reactor from the top to the bottom and passed through pack-bed fuel; this was represented by a resistance flow, turbulence flow, and porous media model. Combustion and gasification occurred on the bed of the reactor. These processes were represented by the Lagrangian discrete phase model or the discrete phase model in the ANSYS Fluent software. The discrete phase model can be set up and address multiple char reactions for solid fuel combustion. The UDF was built in $\mathrm{C}$ code and was used to control the discrete phase model. Governing equations are presented in Table 1.

\subsubsection{Turbulence flow model}

In a downdraft reactor, wood pellet fuel is stacked in packbed mode. The air passes through the pack-bed fuel as turbulent flow. Turbulent flow is represented by the $k-\varepsilon$ model similar to the flow characteristics in the experiment. The first variable is kinetic energy of turbulence $(k)$ and the second variable is the rate of dissipation of turbulence energy $(\varepsilon)$ as shown below.

\subsubsection{Porous media model}

The porous media model represents pack-bed fuel demonstrating resistance flow. There are two momentum source terms: (1) viscous loss and (2) inertial loss which are described as:

(1) Turbulence flow model (Launder and Sharma 1974)

$$
\begin{aligned}
\frac{\partial}{\partial t}(\rho k)+\frac{\partial}{\partial x_{i}}\left(\rho k u_{i}\right)= & \frac{\partial}{\partial x_{j}}\left[\left(\mu+\frac{\mu_{t}}{\sigma_{k}}\right) \frac{\partial k}{\partial x_{j}}\right]+G_{\mathrm{k}} \\
& +G_{\mathrm{b}}-\rho \varepsilon-Y_{\mathrm{M}}+S_{\mathrm{k}} \\
\frac{\partial}{\partial t}(\rho \varepsilon)+\frac{\partial}{\partial x_{i}}\left(\rho \varepsilon u_{i}\right)= & \frac{\partial}{\partial x_{j}}\left[\left(\mu+\frac{\mu_{t}}{\sigma_{\varepsilon}}\right) \frac{\partial \varepsilon}{\partial x_{j}}\right]+C_{1 \varepsilon} \frac{\varepsilon}{k} \\
& +\left(G_{\mathrm{k}}+C_{3 \varepsilon} G_{\mathrm{b}}\right)-C_{2 \varepsilon} \rho \frac{\varepsilon^{2}}{k} \\
& +S_{\varepsilon}
\end{aligned}
$$

(2) Porous media model (Hassanizadeh and Gray 1980)

$$
S_{i}=-\left(\sum_{j=1}^{3} D_{i j} \mu v_{j}+\sum_{j=1}^{3} C_{i j} \frac{1}{2} \rho|v| v_{j}\right)
$$

\subsubsection{Energy and species transport equations}

Combustion and gasification in the reactor are represented by chemical reactions. The chemical reactions in the model can be calculated by the enthalpy of formations and the species transport equations presented as:

(1) Enthalpy

$$
\begin{aligned}
& H=h+\Delta H \\
& h=h_{\text {ref }}+\int_{T_{\text {ref }}}^{T} c_{\mathrm{p}} \mathrm{d} T
\end{aligned}
$$

(2) Species transport equation 


$$
\frac{\partial}{\partial t}\left(\rho Y_{i}\right)+\nabla \cdot\left(\rho \vec{v} Y_{i}\right)=-\nabla \cdot \overrightarrow{J_{i}}+R_{i}+S_{i}
$$

(3) Energy balance equation

$$
\rho c_{\mathrm{p}} \frac{\partial T}{\partial t}=k \nabla^{2} T+\dot{q} v
$$

\subsubsection{Turbulence-chemistry interaction model}

Turbulence-chemistry interaction models control a chemical reaction rate. Combustion and gasification reaction rates are represented by the Laminar finite-rate and Eddydissipation models in the ANSYS-Fluent software (Kerstein 1992). The Laminar finite-rate of turbulence-chemistry interaction and the Eddy-dissipation models are presented as

(1) Laminar finite-rate of turbulence-chemistry interaction

$$
R_{i}=M_{\mathrm{w}, \mathrm{i}} \sum_{r=1}^{N_{R}} \hat{R}_{i, \mathrm{r}}
$$

(2) Eddy-dissipation of turbulence-chemistry interaction

$$
\begin{aligned}
R_{i, \mathrm{r}} & =v_{i, r}^{\prime} M_{\mathrm{w}, \mathrm{i}} A \rho \frac{\varepsilon}{\kappa} \min _{\Re}\left(\frac{Y_{\Re}}{v_{\Re, r}^{\prime} M_{\mathrm{w}, \Re}}\right) \\
R_{i, r} & =v_{i, r}^{\prime} M_{\mathrm{w}, \mathrm{i}} A B \rho \frac{\varepsilon}{\kappa} \frac{\sum_{p} Y_{\mathrm{p}}}{\sum_{j}^{N} v_{j, r}^{\prime \prime} M_{\mathrm{w}, \mathrm{j}}}
\end{aligned}
$$

\subsubsection{The Lagrangian discrete phase model}

In gasification and combustion processes, wood pellets are converted to gaseous products and ash. The processes occur continuously so the Lagrangian discrete phase model can be used. The Lagrangian discrete phase model consists of trajectory calculations as well as heat and mass transfer calculations; spray modeling and coupling between the discrete and the continuous phases and so forth can also be
Fig. 1 Concept of the simulation work in this study: a computational model of downdraft gasification; b flowchart of the simulation algorithm

conducted. In this work, particle force balance, heat balance, the constant rate devolatilization law, and the diffusion-limited surface reaction rate were utilized (Baum and Street 1971) while the drag force was calculated by the equations shown as below:

(1) Particle force balance equation

$$
\frac{\mathrm{d} u_{p}}{\mathrm{~d} t}=F_{\mathrm{D}}\left(u-u_{\mathrm{p}}\right)+\frac{g_{x}\left(\rho_{\mathrm{p}}-\rho\right)}{\rho_{\mathrm{p}}}+F_{x}
$$

(2) Heat balance equation

$$
m_{\mathrm{p}} c_{\mathrm{par}} \frac{\mathrm{d} T_{\mathrm{p}}}{\mathrm{d} t}=h_{\mathrm{c}} A_{\mathrm{p}}\left(T_{\infty}-T_{\mathrm{p}}\right)+\varepsilon_{\mathrm{p}} A_{\mathrm{p}} \sigma\left(\theta_{R}^{4}-T_{\mathrm{p}}^{4}\right)
$$

(3) Constant rate devolatilization law

$$
-\frac{1}{f_{v, 0}\left(1-f_{\mathrm{w}, 0}\right) m_{\mathrm{p}, 0}} \frac{\mathrm{d} m_{\mathrm{p}}}{\mathrm{d} t}=A_{0}
$$

(4) Diffusion-limited surface reaction rate

$$
\frac{\mathrm{d} m_{\mathrm{p}}}{\mathrm{d} t}=-4 \pi d_{\mathrm{p}} D_{i, \mathrm{~m}} \frac{Y_{O X} T_{\infty} \rho_{\mathrm{g}}}{S_{\mathrm{b}}\left(T_{\mathrm{p}}+T_{\infty}\right)}
$$

\section{Drag force}

$$
F_{\mathrm{D}}=\frac{18 \mu}{\rho_{\mathrm{p}} d_{\mathrm{p}}^{2}} \frac{C_{\mathrm{D}} R e}{24}
$$

\subsection{Geometry and mesh shape}

The geometry of the gasifier in this study with all the computational models and simulation algorithms is presented in Fig. 1. In the reactor, the air flow direction was downwards so the porous media model was used for resistance flow that affected the pack-bed of wood pellets in the reactor. Gasification and combustion processes occurred at the bottom of the reactor. Two-dimensional

Table 1 Governing equations

\begin{tabular}{ll}
\hline Applicable scenario & Equation \\
\hline Conservation of mass & $\int_{V}\left[\frac{D_{\rho}}{D t}+\rho \nabla \cdot v\right] \mathrm{d} V=0$ \\
Conservation of linear momentum & $\int_{V}\left[\frac{\partial}{\partial t}[\rho v]+\nabla \cdot\{\rho v v\}-f\right] \mathrm{d} V=0$ \\
Conservation of energy & $\int_{V}\left[\frac{\partial}{\partial t}[\rho e]+\nabla \cdot[\rho v e]+\nabla \cdot \dot{q}_{s}+\nabla \cdot[p v]-\nabla \cdot[\tau \cdot v]-f_{b} \cdot v-\dot{q}_{V}\right] \mathrm{d} V=0$ \\
General convection equation & $\frac{\partial}{\partial t}(\rho \phi)+\nabla \cdot(\rho v \phi)=\nabla \cdot\left(\Gamma^{\phi} \nabla \phi\right)+Q^{\phi}$ \\
\hline
\end{tabular}



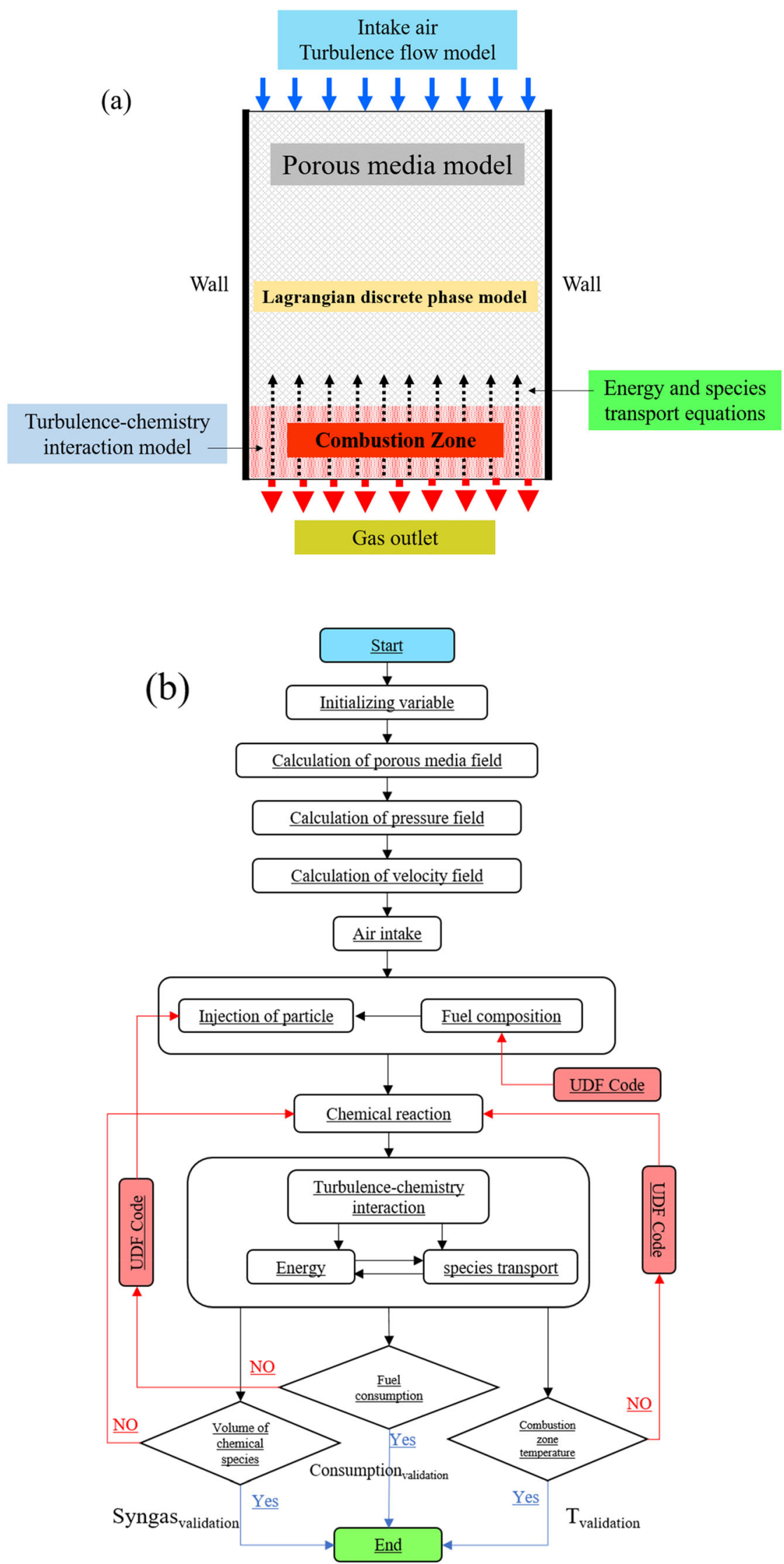
Table 2 Heterogeneous and homogeneous reactions in the downdraft gasifier (Pandey et al. 2019)

\begin{tabular}{ll}
\hline Chemical reaction & $\Delta H(\mathrm{~kJ} / \mathrm{mol})$ \\
\hline Heterogeneous reactions & \\
$\mathrm{C}_{\mathrm{s}}+0.5 \mathrm{O}_{2} \rightarrow \mathrm{O}$ & -123.1 \\
$\mathrm{C}_{\mathrm{s}}+\mathrm{O}_{2} \rightarrow \mathrm{CO}_{2}$ & -393.5 \\
$\mathrm{C}_{\mathrm{s}}+\mathrm{H}_{2} \mathrm{O} \rightarrow \mathrm{H}_{2}+\mathrm{CO}$ & 118.5 \\
$\mathrm{C}_{\mathrm{s}}+2 \mathrm{H}_{2} \rightarrow \mathrm{CH}_{4}$ & -87.5 \\
$\mathrm{C}+\mathrm{CO}_{2} \rightarrow 2 \mathrm{CO}$ & 159.9 \\
Homogeneous reactions & \\
$\mathrm{CO}+\mathrm{H}_{2} \mathrm{O} \rightarrow \mathrm{H}_{2}+\mathrm{CO}_{2}$ & -40.9 \\
$2 \mathrm{CO}+\mathrm{O}_{2} \rightarrow 2 \mathrm{CO}$ & -283 \\
$\mathrm{CH}+\mathrm{H}_{2} \mathrm{O} \rightarrow \mathrm{CO}+3 \mathrm{H}_{2}$ & 206 \\
$\mathrm{CH}_{4}+0.5 \mathrm{O}_{2} \rightarrow \mathrm{CO}+2 \mathrm{H}_{2}$ & -110 \\
\hline
\end{tabular}

Table 3 Summary of model setup and boundary conditions

\begin{tabular}{lll}
\hline \multirow{2}{*}{ Direction } & \multicolumn{2}{c}{ Resistance flow parameters } \\
\cline { 2 - 3 } & Viscous resistance $\left(\mathrm{m}^{-2}\right)$ & Inertial resistance $\left(\mathrm{m}^{-1}\right)$ \\
\hline$X$ & $161,915.4$ & 189.4 \\
$Y$ & 189.4 & \\
\hline Boundary conditions & & 0.056 \\
\hline Inlet velocity magnitude $(\mathrm{m} / \mathrm{s})$ & 300 \\
Inlet temperature $(\mathrm{K})$ & 0.23 \\
Inlet species mass fraction of $\mathrm{O}_{2}$ & Stationary \\
Wall motion & & No slip \\
Wall shear condition & Standard \\
Wall roughness & 0 \\
Outlet gauge pressure & 300 \\
Outlet temperature $(\mathrm{K})$ & \\
\hline
\end{tabular}

geometry was utilized and the mesh shape was rectangular. The mesh size was $6.2198 \times 10^{-5} \mathrm{~m}$.

\subsection{Model setup and boundary conditions}

In CFD modeling, the energy equation is employed for enthalpy of chemical reaction calculations. The realizable $k-\varepsilon$ and the porous media models were used for the turbulence model and resistance flow modeling, respectively. The species transport model and the discrete phase model allowed for chemical reaction calculations and particleinjecting tracking simulation, respectively. Particle injection models were crafted by an in-house coded UDF to control devolatilization, gasification, and combustion processes in our downdraft gasifier. Heterogeneous and
Table 4 Fuel properties of the wood pellets

\begin{tabular}{ll}
\hline Item & Value \\
\hline Proximate analysis (as received basis) & \\
Moisture (wt\%) & 7.19 \\
Fixed carbon (wt\%) & 18.43 \\
Ash (wt\%) & 1.36 \\
Volatile (wt\%) & 73.02 \\
Ultimate analysis (dry basis) & \\
$\mathrm{C}(\mathrm{wt} \%)$ & 44.86 \\
$\mathrm{H}(\mathrm{wt} \%)$ & 5.58 \\
$\mathrm{~N}(\mathrm{wt} \%)$ & 1.81 \\
$\mathrm{O}(\mathrm{wt} \%)$ & 39.21 \\
Heating value (dry basis) & \\
HHV (kJ/kg) & 17,732 \\
LHV (kJ/kg) & 16,343 \\
Chemical formula & $\mathrm{CH}_{1.4926} \mathrm{O}_{0.655} \mathrm{~N}_{0.03458}$ \\
\hline
\end{tabular}

homogenous reactions are summarized in Table 2. The boundary conditions of air flow and resistance flow used in the model are presented in Table 3. For the simulation, the time step was $10 \mathrm{~s}$. CFD modeling was run from 0 to $7200 \mathrm{~s}$ for the experiment's duration.

\subsection{Experimental setup}

Wood pellets ( $8 \mathrm{~mm}$ in diameter, $4-5 \mathrm{~cm}$ in length) were produced from sawdust using the pelleting process. Their properties are shown in Table 4. The downdraft gasifier produced $10 \mathrm{~kW}$ of thermal energy. The size and the height of the reactor were 250 and $345 \mathrm{~mm}$, respectively. The components of the downdraft gasifier are shown in Fig. 2. The experiment's results concerned the temperature at the combustion zone, fuel consumption during the gasification process, and syngas composition. The flow rate of air in the experiment was constant at $7.11 \mathrm{~m}^{3} / \mathrm{h}$. The equivalence ratio during the steady state was 0.23 . The thermocouple type $\mathrm{K}$ model installed at $120 \mathrm{~mm}$ from the bottom of reactor was used to measure the combustion zone temperature. Fuel consumption was measured by the reduction of wood pellet weight in the reactor during the experiment. The syngas compositions were measured by gas chromatography in steady state condition and were collected during the $7200 \mathrm{~s}$ of the experiment. The syngas was sampled by a gas collection unit equipped with 5 impinger bottles filled with $200 \mathrm{~mL}$ of isopropyl alcohol and 1 impinger bottle with desiccant to remove moisture. The temperature of the impinger set was $0{ }^{\circ} \mathrm{C}$. Then, the vacuum pump was utilized for syngas sampling by the gas bag. Finally, the collected syngas was analyzed by gas chromatograph (Agilent GC 7890B) equipped with a thermal 


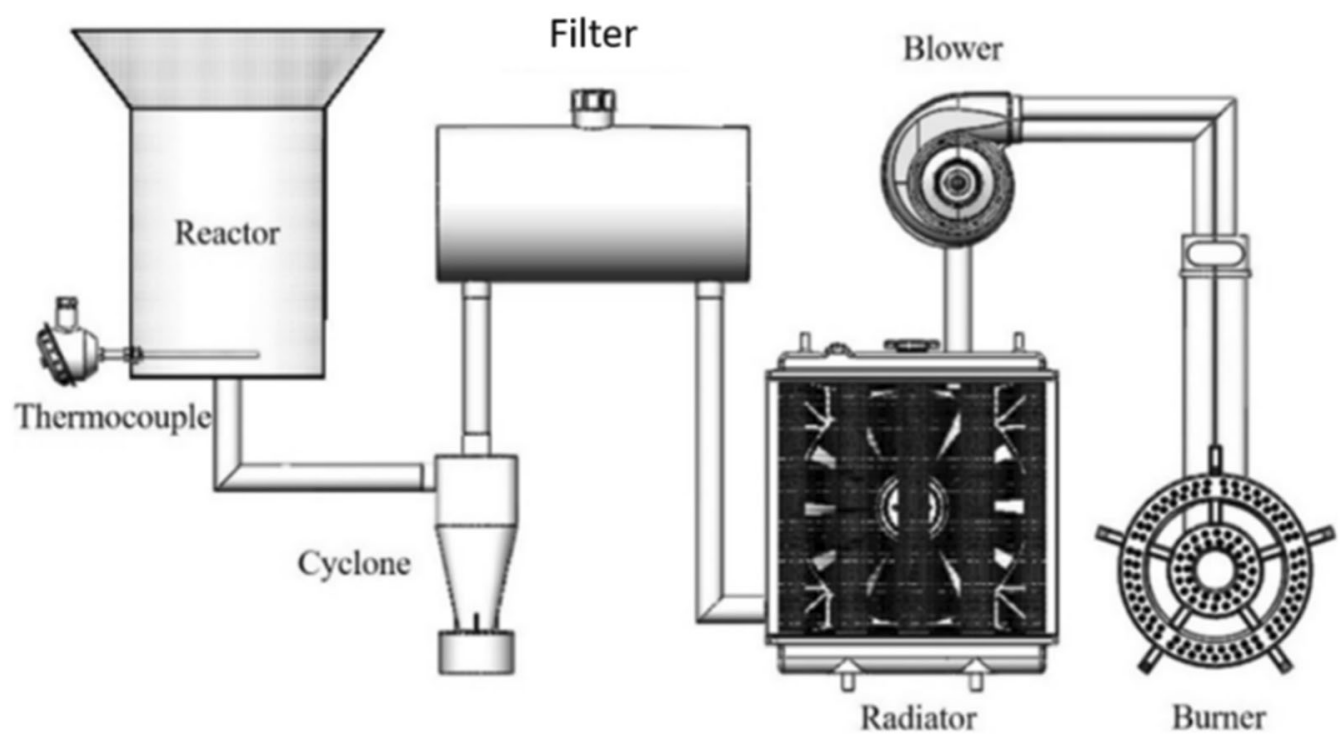

Fig. 2 Schematic of the down-draft stove and equipment used in the experiment

conductivity detector (TCD) following a $10 \mathrm{ft}$ long $1 / 8 \mathrm{in}$. diameter MolSieve 13X column and $6 \mathrm{ft}$ long $1 / 8 \mathrm{in}$. diameter Porapak Q 80-100 mesh column.

\section{Model validation}

\subsection{Fuel consumption during the gasification process}

The fuel consumption results of the CFD model were measured by the flow rate of mass injection to the reactor. The fuel consumption profile is shown in Fig. 3a. The wood pellet fuel was gradually consumed from the beginning of the gasification process, i.e. the transient period. It reached steady state when the wood pellet consumption rate of the gasifier was relatively constant. Fuel consumption approached steady state at around 2400-3000 s. Validation of simulated wood pellet consumption and experimental results are presented in Fig. 3b, which shows a marginal difference during the steady state period. The conversion of solid fuel to syngas can be explained by the reduction of the mass of solid fuel and the increase of synthesis gas. The experiment indicated that the wood pellet consumption rate during steady state was $1.750 \pm 0.048 \mathrm{~g} / \mathrm{s}$ or approximately $6.3 \mathrm{~kg} / \mathrm{h}$. With a similar ER (0.2-0.3), the fuel consumption of wood pellets was significantly lower than that of rice husks $(18.612-23.875 \mathrm{~kg} / \mathrm{h})$ due to the better fuel quality of the wood pellets (low ash content) (Murugan and Sekhar 2017). Validation of fuel consumption is the foundation for other parameter modeling. The wood pellet consumption model was developed by the UDF which successfully controlled the rate of fuel consumption with error of less than $2 \%$.

\subsection{Temperature profile in the reactor}

The simulation results of the temperature in the downdraft gasifier are presented in Fig. 4a. The temperature in the combustion zone was recorded every $10 \mathrm{~s}$ from 0 to 7200 s. The temperature profile exhibited two stages, i.e. transient and steady states. The former was the period during 0-3000 s, during which the temperature increased rapidly. The temperature of the combustion zone during the transient stage showed similar characteristics to the work of Akay and Jordan (2011). Subsequently, the temperature profile reached steady state which was approximately $1240.32 \mathrm{~K}$. The temperature during steady state was relatively constant.

Figure $4 \mathrm{~b}$ shows temperature distribution in the downdraft gasifier. The contour of temperature from the simulation well represents the downdraft gasifier characteristic where the intake air flows from the top to the bottom of the reactor (Richardson et al. 2015). The fresh air suppressed an increase of temperature in the middle of the gasifier reactor which differed from the temperature contour of the updraft gasifier (Lu et al. 2018). Comparison of simulated and experimental results is shown in Fig. 4c. The error of temperature between the developed model and experimental model in the steady state period can be represented by the different steady state average temperature values. The average temperature of the experimental and simulated results was $1240.32 \pm 14.20$ and $1256.46 \pm 9.90 \mathrm{~K}$, 
respectively. Thus, the difference of average steady state temperature was $16.14 \mathrm{~K}$. The temperature profile of the developed model was higher than the temperature of the experimental model by about $1.3 \%$ which may be due to heat loss in the wall of the reactor that was negligible in the developed model.

\subsection{Syngas composition analysis}

Figure $5 \mathrm{a}, \mathrm{b}$ present syngas composition and distribution of each synthesis gas species in the gasifier, respectively. The results are presented by the volume of each species, namely, $\mathrm{CO}, \mathrm{CO}_{2}, \mathrm{H}_{2}$, and $\mathrm{CH}_{4}$. The profile shows the
Fig. 4 Validation of temperature in the downdraft gasifier: a simulation results of the combustion zone; $\mathbf{b}$ distribution temperature in the reactor at $7200 \mathrm{~s}$; c comparison of simulation and experimental results

volume of each product every $10 \mathrm{~s}$ from 0 to $7200 \mathrm{~s}$. The contour of the syngas shows the result at $7200 \mathrm{~s}$. In the transient period, the production of syngas increased rapidly until steady state condition was reached. This syngas evolution characteristic was observed in a $50 \mathrm{kWe}$ downdraft gasifier using bagasse as feedstock (Akay and Jordan 2011).
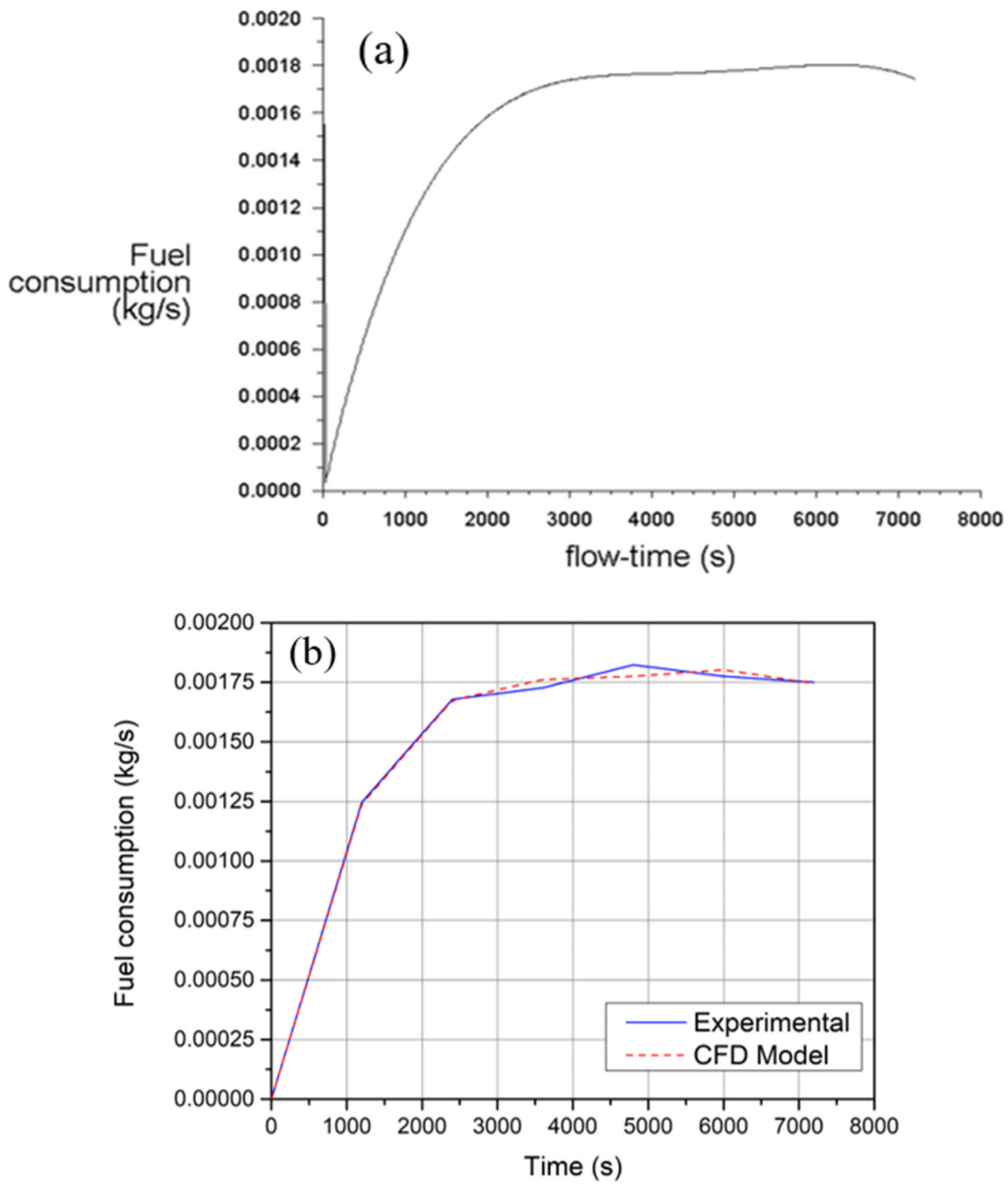

Fig. 3 Validation of fuel consumption results: a simulated fuel consumption during gasification; b comparison of the simulated and experimental results 


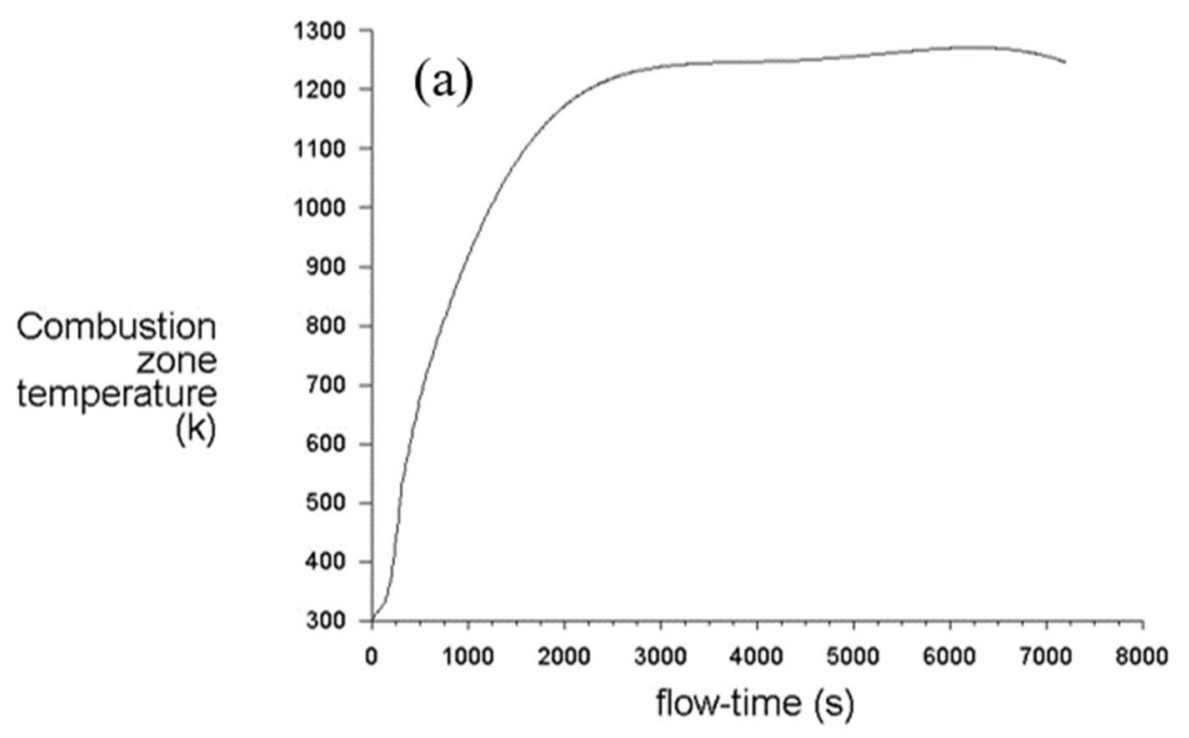

(b)

cortoust
Sasoc Temperature
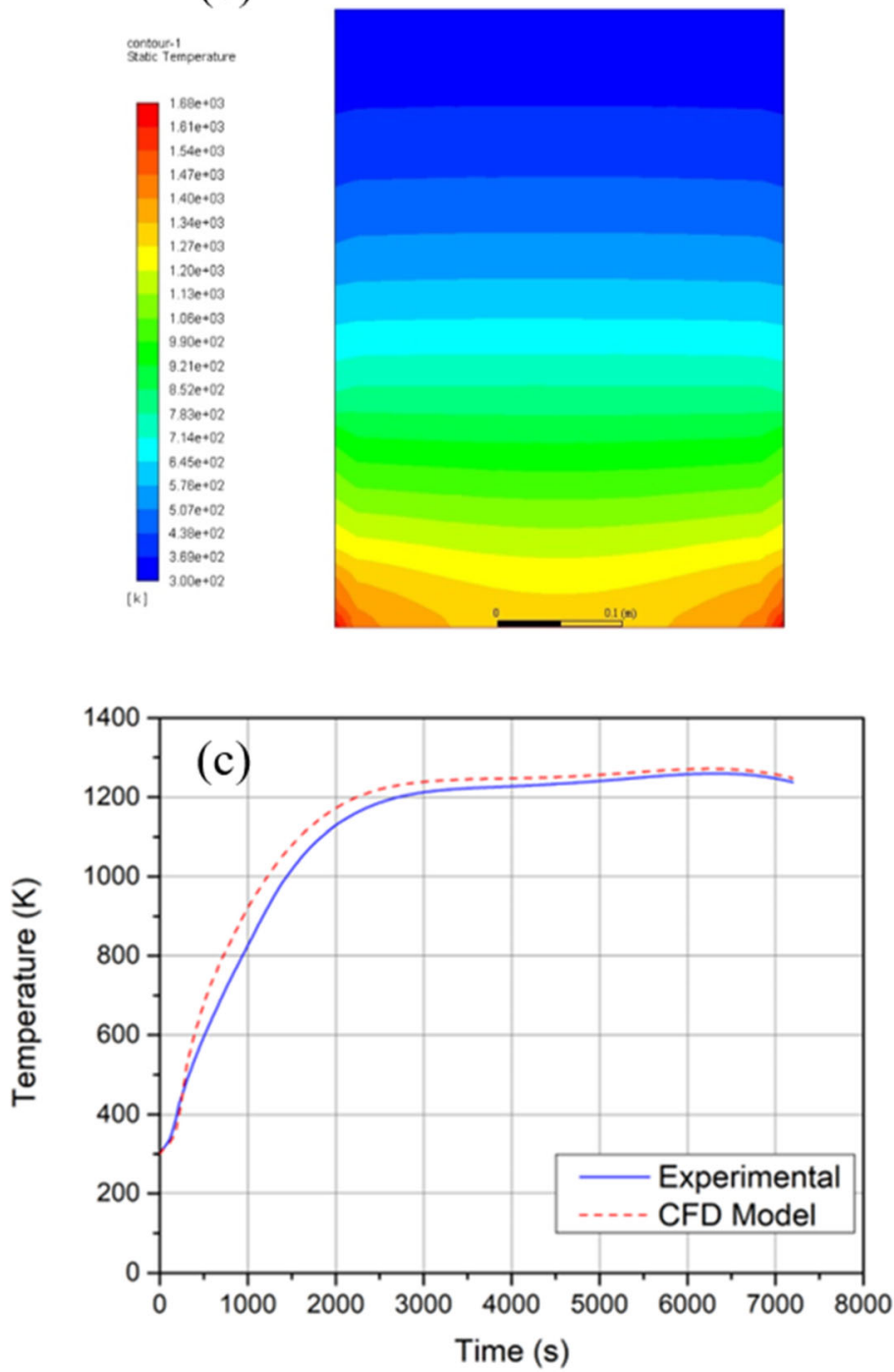
The distribution of $\mathrm{CO}$ in the reactor was highly concentrated in the bottom and the middle of the reactor. It seemed to be distributed throughout the cross-section of the reactor. A similar contour can be observed in the $\mathrm{H}_{2}, \mathrm{CO}_{2}$, and $\mathrm{CH}_{4}$ species. Contour syngas distribution has a distinct characteristic. High concentration of syngas was observed in the outer radial part of the reactor owing to the air flow of the downdraft gasifier descending from the top and passing through the wood pellet bed (the flow was represented as the resistance flow model). The flow of air forced the synthesis gas stream to move to the outer part of the gasifier represented by the contour of syngas distribution. The radial distribution is clearly observed at the bottom section of the reactor where the reactions occurred. This phenomenon was also observed in other downdraft gasifier simulations (Kumar and Paul 2019). The profile of syngas composition from the model is presented in Fig. 6a and compared with the syngas sampling results. The concentrations of $\mathrm{H}_{2}$ and $\mathrm{CH}_{4}$ from the model and experiment were very close throughout the profile while the concentrations of $\mathrm{CO}_{2}$ and $\mathrm{CO}$ showed fluctuations at the beginning of the test. However, the trend of syngas evolution from both model and experiment were relatively consistent and comparable. The profiles of syngas composition and evolution were matched with the experimental work of (Yucel and Hastaoglu 2016). From the steady-state simulation results at $7200 \mathrm{~s}$, Fig. 6b shows that the concentrations of $\mathrm{CO}, \mathrm{CO}_{2}, \mathrm{H}_{2}$, and $\mathrm{CH}_{4}$ were 20.42 vol\%, $15.09 \mathrm{vol} \%, 8.02 \mathrm{vol} \%$, and $2.60 \mathrm{vol} \%$. The composition of the synthesis gas from the experiment at $7200 \mathrm{~s}$ was $20.00 \mathrm{vol} \%, 15.48 \mathrm{vol} \%, 8.00 \mathrm{vol} \%$, and $2.65 \mathrm{vol} \%$. The error of syngas volume fractions at the steady state was $2.10 \%, 2.52 \%, 0.25 \%$, and $1.89 \%$ for $\mathrm{CO}, \mathrm{CO}_{2}, \mathrm{H}_{2}$, and $\mathrm{CH}_{4}$, respectively. Thus, the syngas composition results from the simulation model were validated by the experimental results.

Syngas composition from this study was compared with other experimental data and models as shown in Fig. 7. It was observed that the syngas gas composition correlated with the references. $\mathrm{CO}$ contributed the highest concentration followed by $\mathrm{CO}_{2}, \mathrm{H}_{2}$ and $\mathrm{CH}_{4}$. However, the model from this study showed relatively high $\mathrm{CO}_{2}$ concentration in the syngas composition.

\section{Results and discussion}

Comparison of the simulation and experimental results revealed that the model developed in this work can be validated. In this section, the validated model is utilized for investigation on the effect of the aspect ratios on the temperature and synthesis gas composition of the downdraft gasification process.
Fig. 5 Validation of syngas composition: a syngas composition profile; b syngas distribution in the reactor at $7200 \mathrm{~s}$

\subsection{Implication of the simulation model for gasifier design}

The downdraft gasifier is an appropriate choice for stable and clean syngas production. The size of the reactor can be adjusted during the gasifier design by changing the ratio of height and diameter or the aspect ratio $(H / D)$. Several parameters were investigated in this study: (1) Transient time, (2) Temperature profile, (3) Steady state final temperature, and (4) Syngas composition. In the developed model, the aspect ratio was 1.38 and the transient duration was about $3000 \mathrm{~s}$. The predicted gasifier design after changing the aspect ratio is presented in Table 5. The aspect ratios used in the design were 1.00, 1.38 (default) and 1.82, respectively.

\subsection{Temperature profile prediction}

Figure $8 \mathrm{a}$ shows the temperature profile of the downdraft gasifier with different aspect ratios. The transient time had no significant difference when the aspect ratios were changed. However, the average temperatures during steady state of the $H / D=1.00,1.38$, and 1.82 aspect ratios were $978.77 \pm 11.60,1256.46 \pm 9.91$, and $1368.94 \pm 9.20 \mathrm{~K}$, respectively. The gasifier with the aspect ratio of $1.82 \mathrm{had}$ steady state temperature higher than those of the 1.00 and 1.38 aspect ratio gasifiers. This may be because the diameter of the 1.82 aspect ratio reactor was the smallest, and this may have affected the radiative heat transfer from the reactor wall. A more compact gasifier design could increase the average steady state final temperature. From the prediction, the gasifier of the $1.00 H / D$ aspect ratio had the lowest steady state temperature (about $1000 \mathrm{~K}$ ) but it was still acceptable for the design. However, the steady state temperature should not be lower than $900 \mathrm{~K}$ because devolatilization varies between 600 and $900 \mathrm{~K}$ (Higman 2008; Rezaiyan and Cheremisinoff 2005) and low temperature reduces carbon conversion during the gasification process.

\subsection{Syngas composition prediction}

The volume fraction of the syngas produced from different aspect ratios is presented in Fig. $8 \mathrm{~b}$. The $\mathrm{CO}, \mathrm{CO}_{2}, \mathrm{H}_{2}$, and $\mathrm{CH}_{4}$ concentrations of the reactor with the aspect ratio of 1.00 were $20.26 \%, 14.77 \%, 8.18 \%$, and $2.92 \%$, respectively. When the aspect ratio of the reactor was increased to 1.82 , the volumetric yields of $\mathrm{CO}, \mathrm{CO}_{2}, \mathrm{H}_{2}$, and $\mathrm{CH}_{4}$ were 

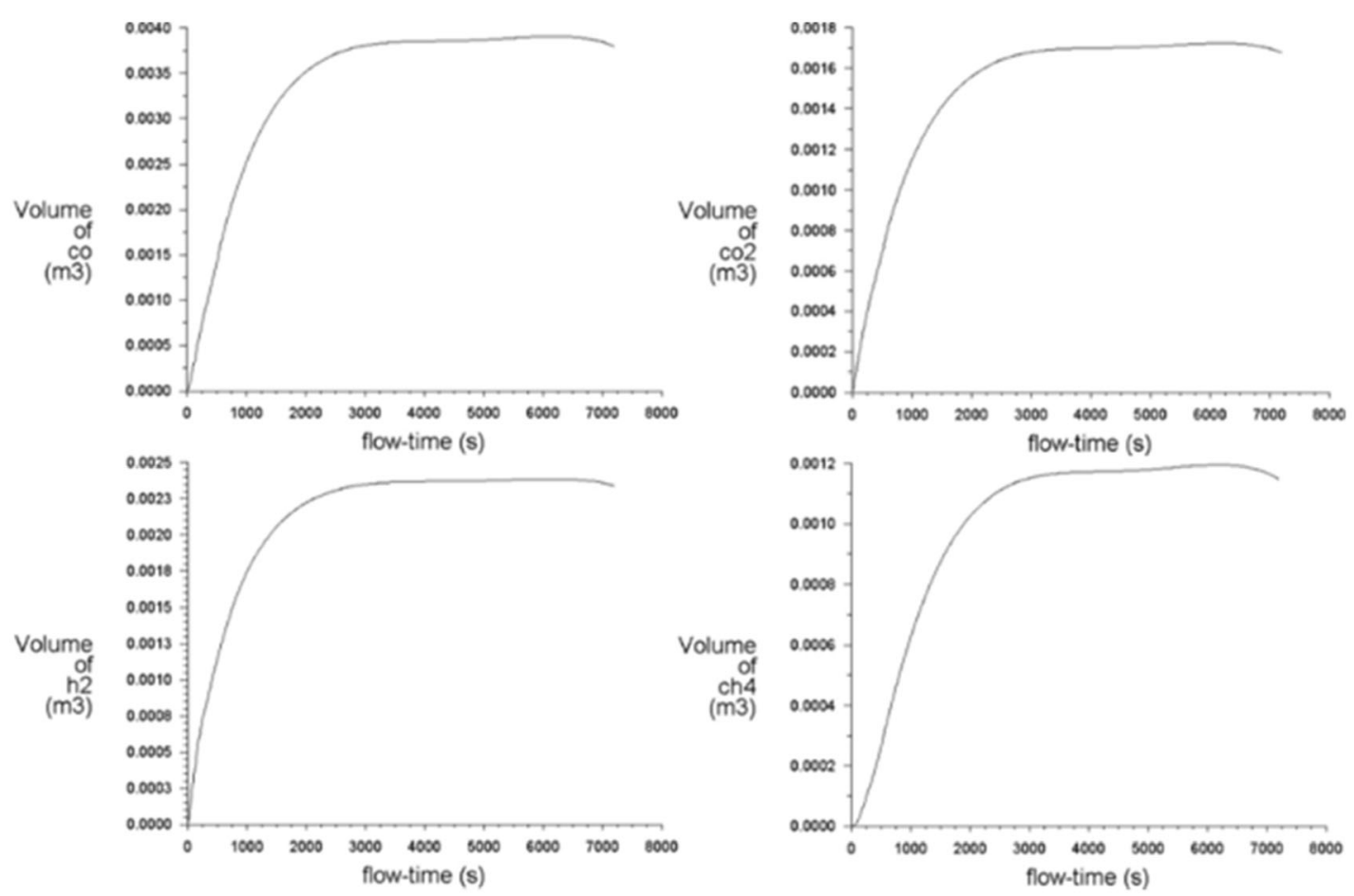

(a)
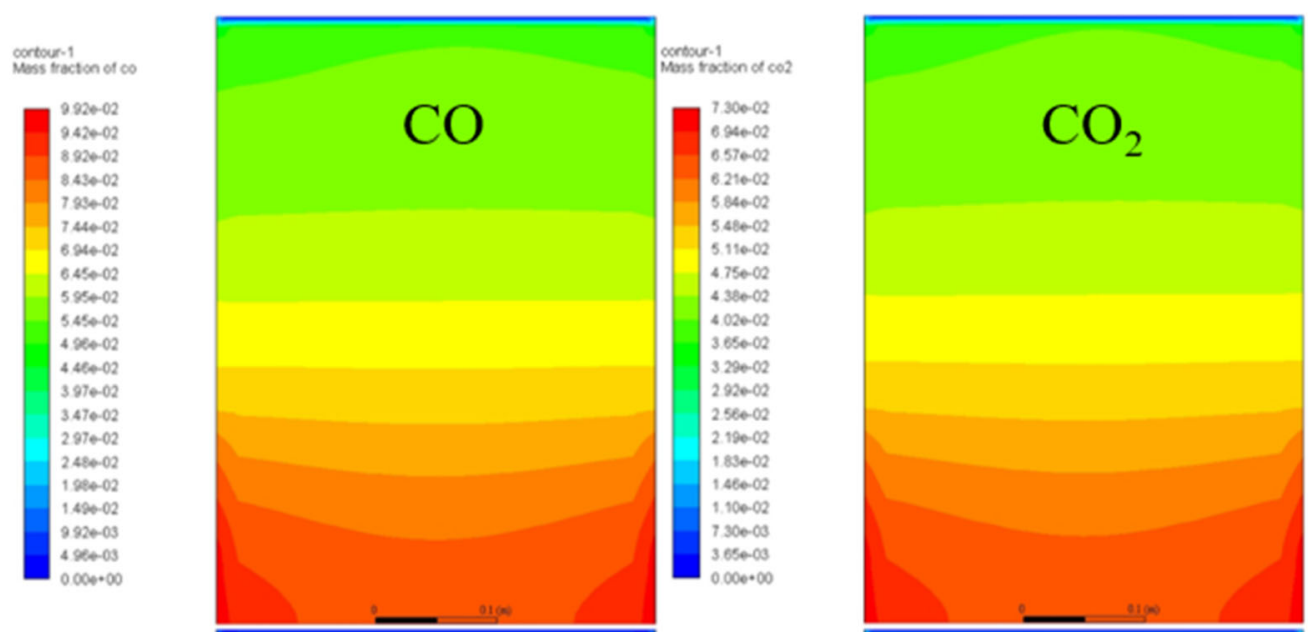

sortours-1.

$6240-02$

$5924-02$

5.610-02

5.300-02

$4900-02$

$4604-02$

$4370-02$

$4050-02$

$3740-02$

3.436-02

3. $120-02$

$2.810-02$

249602

$2.160-02$

$1.870-02$

$1560-02$

1. $250-02$

$0360-03$

$6240-03$

$3120-03$

000000
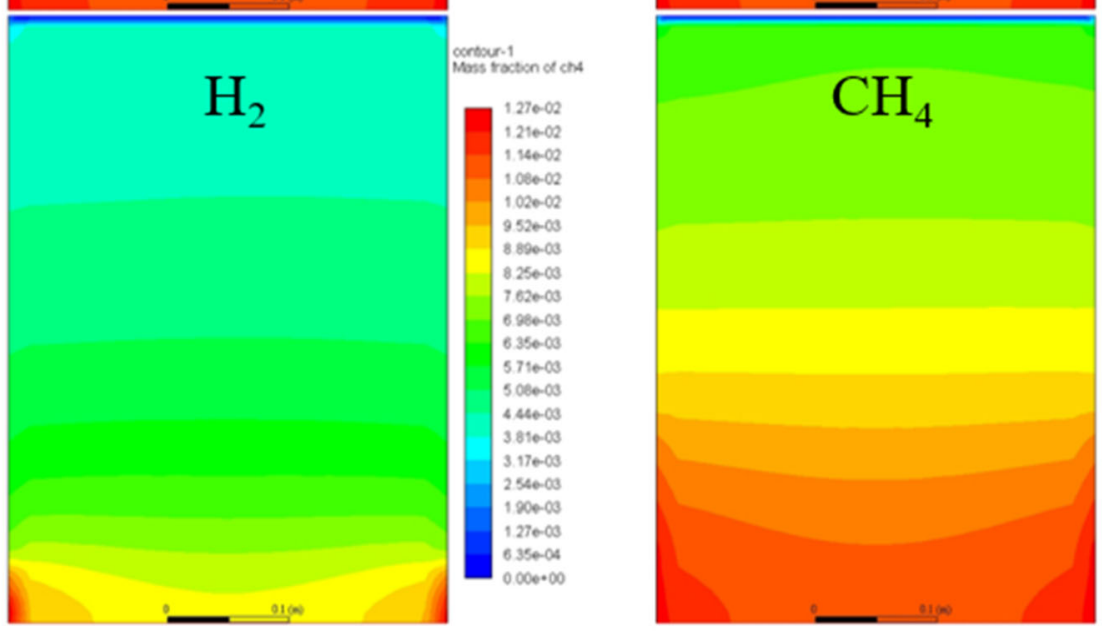

(b) 

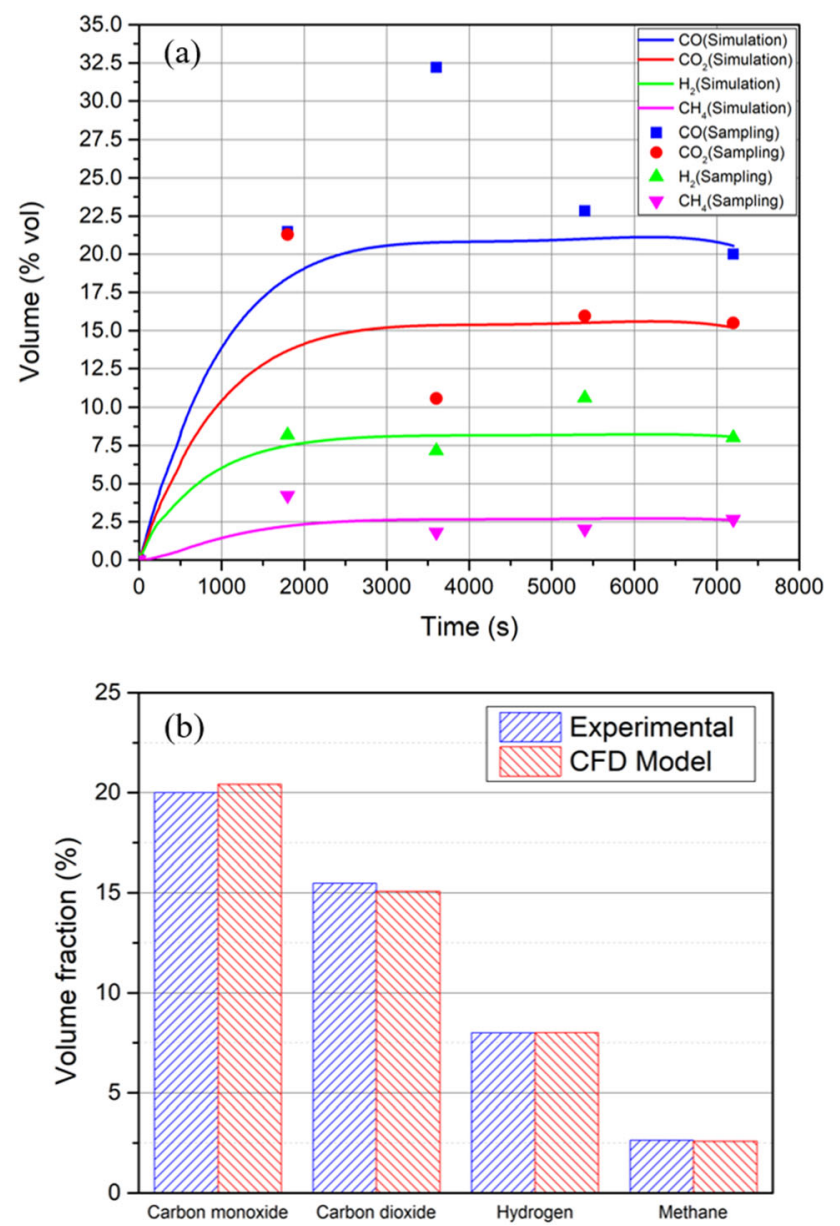

Fig. 6 Syngas results: a composition of syngas from the simulation and sampling results; $\mathbf{b}$ comparison of synthesis gas results

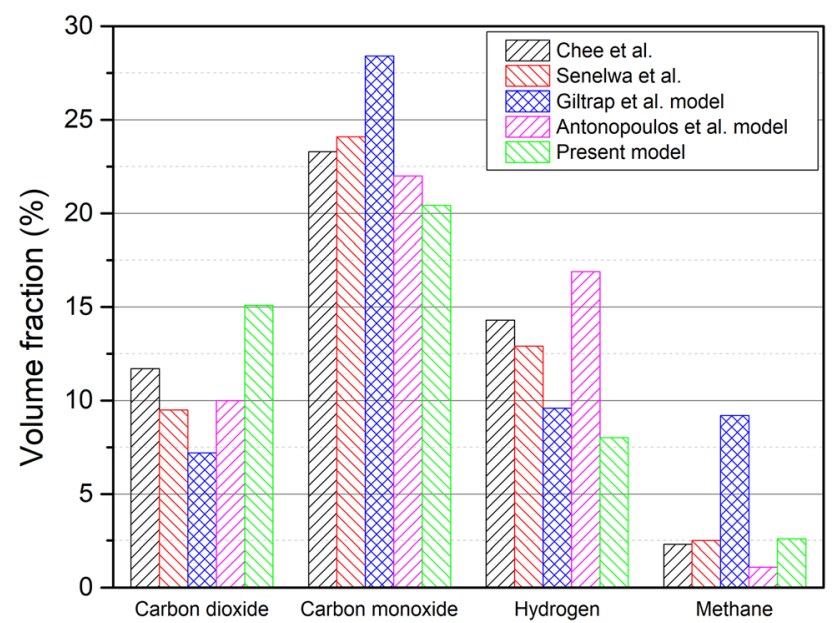

Fig. 7 Comparison of syngas composition in models developed by Chee (1987), Senelwa (1997) and Antonopoulos et al. (2012) and the present model

$20.17 \%, 15.05 \%, 8.64 \%$, and $2.27 \%$, respectively. $\mathrm{CO}_{2}$ and $\mathrm{H}_{2}$ volume fractions increased in the case of the high aspect
Table 5 Dimension of the reactor model

\begin{tabular}{llll}
\hline Reactor model & Volume $\left(\mathrm{m}^{3}\right)$ & Height $(\mathrm{m})$ & Diameter $(\mathrm{m})$ \\
\hline$H / D=1.00$ & 0.0169 & 0.2783 & 0.2783 \\
$H / D=1.38$ & 0.0169 & 0.3450 & 0.2500 \\
$H / D=1.82$ & 0.0169 & 0.4150 & 0.2280 \\
\hline
\end{tabular}
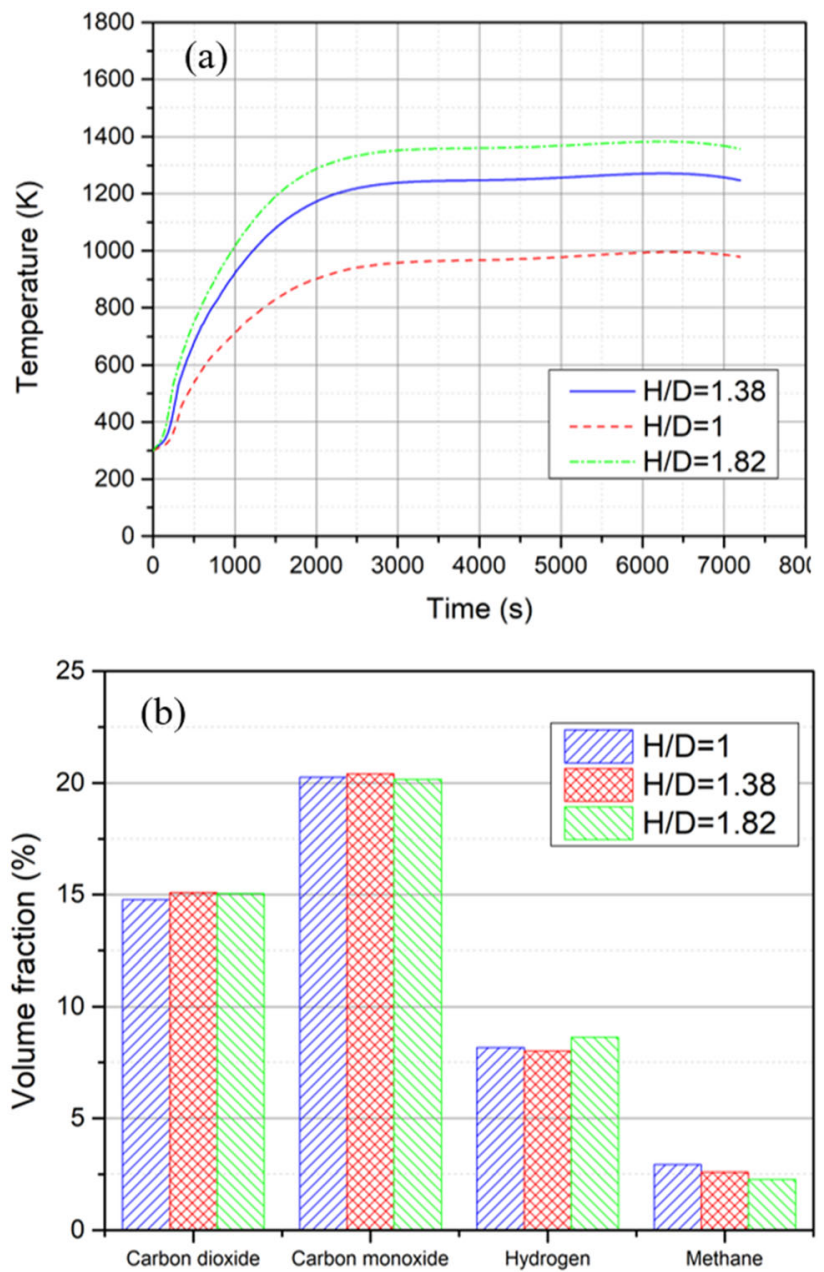

Fig. 8 Variation of gasifier aspect ratios: a temperature profile prediction; b syngas volume fraction prediction

ratio reactor whereas the $\mathrm{CH}_{4}$ volume fraction decreased. $\mathrm{H}_{2}$ can be increased with the expense of $\mathrm{CH}_{4}$ through the chemical reaction, i.e. $\mathrm{CH}_{4}+\mathrm{H}_{2} \mathrm{O} \rightarrow \mathrm{CO}+3 \mathrm{H}_{2}$ (Babu and Sheth 2006; Pandey et al. 2019).

\subsection{Prediction of syngas heating value and cold gas efficiency}

Table 6 shows the calculated formula for syngas lower heating value (LHV), cold gas efficiency (CGE), and 
Table 6 Heating value, cold gas efficiency, and carbon conversion calculation formulae

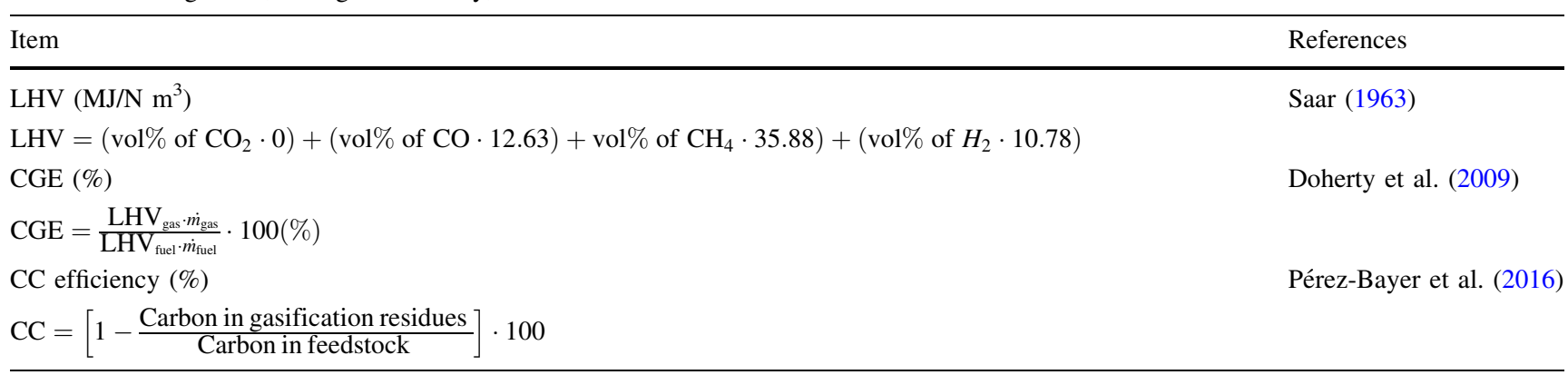

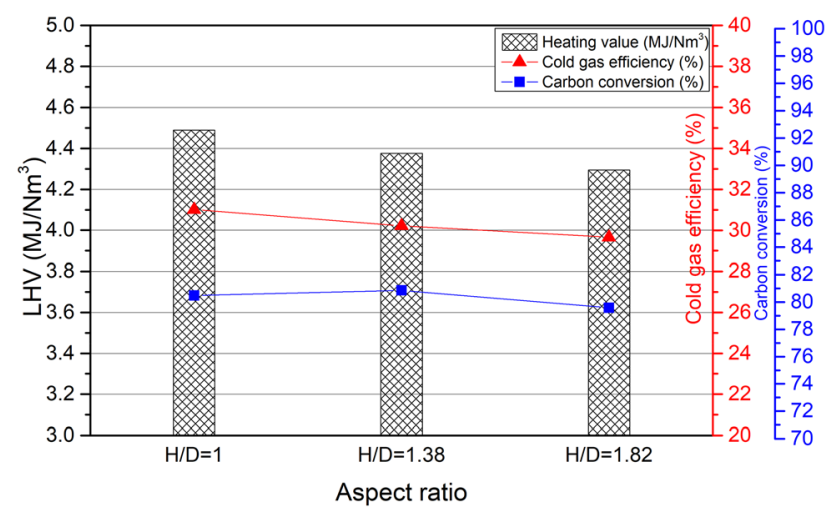

Fig. 9 Prediction of syngas heating value, cold gas efficiency, and carbon conversion efficiency

carbon conversion (CC) of the gasification process. The results are presented in Fig. 9. The LHV of syngas from the downdraft gasification experiment $(H / D=1.38)$ was $4.38 \mathrm{MJ} / \mathrm{N} \mathrm{m}^{3}$. When the aspect ratio was reduced to 1 , the LHV of syngas was increased to $4.49 \mathrm{MJ} / \mathrm{N} \mathrm{m}^{3}$. Conversely, the syngas LHV from the gasifier with the 1.82 aspect ratio was $4.29 \mathrm{MJ} / \mathrm{N} \mathrm{m}^{3}$. These results present the inverse correlation between the aspect ratios and the LHV of the product gas. The CGE of the process was in range of $29.66 \%$ to $31.00 \%$ while CC was $79.59 \%$ to $80.87 \%$. The trend of CGE was similar to the LHV of the syngas; the CGE of a $9.18 \mathrm{~mm}$ woodchip downdraft gasifier was approximately $48 \%$ at ER 0.325 (Jayathilake and Rudra 2017).

\section{Conclusions}

This paper investigated two-dimensional CFD modeling of a downdraft gasifier with pilot-scale experiment verification using wood pellet as fuel. Three main parameters were used in the verification process, namely, fuel consumption, temperature profile, and syngas composition. After the developed model was verified, the effects of aspect ratios on temperature and syngas composition were investigated. It can be concluded that:

(1) The wood pellet consumption rate from the pilotscale downdraft gasification experiment was $1.750 \pm 0.048 \mathrm{~g} / \mathrm{s}$. The error from the simulation result was less than $2 \%$.

(2) The average steady state temperature of the experimental and simulated results was $1240.32 \pm 14.20$ and $1256.46 \pm 9.90 \mathrm{~K}$, respectively, presenting an error of $1.3 \%$.

(3) From the simulation results, the concentrations of each species- $\mathrm{CO}, \mathrm{CO}_{2}, \mathrm{H}_{2}$, and $\mathrm{CH}_{4}$-were $20.42 \mathrm{vol} \%, 15.09 \mathrm{vol} \%, 8.02 \mathrm{vol} \%$, and $2.6 \mathrm{vol} \%$, respectively, which was comparable to the composition of the synthesis gas from the experiment $(20.00 \mathrm{vol} \%, \quad 15.48 \mathrm{vol} \%, \quad 8.00 \mathrm{vol} \%, \quad$ and $2.65 \mathrm{vol} \%)$.

(4) The average temperatures during the steady state of the gasifier with aspect ratios of $H / D 1.00,1.38$, and 1.82 were $978.77 \pm 11.60,1256.46 \pm 9.90$, and $1368.94 \pm 9.20 \mathrm{~K}$, respectively. The 1.82 aspect ratio reactor had the smallest diameter so the radiative heat transferred from the reactor wall affected the temperature in the reactor.

(5) $\mathrm{CO}, \mathrm{CO}_{2}, \mathrm{H}_{2}, \mathrm{CH}_{4}$, concentrations of the reactor aspect ratio 1.00 were $20.26 \%, 14.77 \%, 8.18 \%$, and $2.92 \%$, respectively. When the aspect ratio of the reactor was increased to 1.82 , the volumetric yields of the $\mathrm{CO}, \mathrm{CO}_{2}, \mathrm{H}_{2}, \mathrm{CH}_{4}$ were $20.17 \%, 15.05 \%$, $8.64 \%$, and $2.27 \%$, respectively. $\mathrm{CO}_{2}$ and $\mathrm{H}_{2}$ volume fraction increased in the case of the high aspect ratio reactor whereas the $\mathrm{CH}_{4}$ volume fraction decreased.

(6) The LHV of syngas was in the range of 4.29 to $4.49 \mathrm{MJ} / \mathrm{N} \mathrm{m}^{3}$. Cold gas efficiency of the process was $29.66 \%$ to $31.00 \%$ and carbon conversion was $79.59 \%$ to $80.87 \%$. 
Acknowledgements This research is funded by the Department of Mechanical Engineering, Faculty of Engineering, Kasetsart University. P. Sarabhorn received a scholarship from the Faculty of Engineering, Kasetsart University.

\section{Compliance with ethical standards}

Conflict of interest The authors declare no competing interests.

Open Access This article is licensed under a Creative Commons Attribution 4.0 International License, which permits use, sharing, adaptation, distribution and reproduction in any medium or format, as long as you give appropriate credit to the original author(s) and the source, provide a link to the Creative Commons licence, and indicate if changes were made. The images or other third party material in this article are included in the article's Creative Commons licence, unless indicated otherwise in a credit line to the material. If material is not included in the article's Creative Commons licence and your intended use is not permitted by statutory regulation or exceeds the permitted use, you will need to obtain permission directly from the copyright holder. To view a copy of this licence, visit http://creativecommons. org/licenses/by/4.0/.

\section{References}

Akay G, Jordan CA (2011) Gasification of fuel cane bagasse in a downdraft gasifier: influence of lignocellulosic composition and fuel particle size on syngas composition and yield. Energy Fuel 25(5):2274-2283

Antonopoulos I-S, Karagiannidis A, Gkouletsos A, Perkoulidis G (2012) Modelling of a downdraft gasifier fed by agricultural residues. Waste Manag 32(4):710-718

Babu B, Sheth PN (2006) Modeling and simulation of reduction zone of downdraft biomass gasifier: effect of char reactivity factor. Energy Convers Manag 47(15-16):2602-2611

Bahng M-K, Mukarakate C, Robichaud DJ, Nimlos MR (2009) Current technologies for analysis of biomass thermochemical processing: a review. Anal Chim Acta 651(2):117-138

Baruah D, Baruah D, Hazarika M (2017) Artificial neural network based modeling of biomass gasification in fixed bed downdraft gasifiers. Biomass Bioenergy 98:264-271

Basu P (2013) Biomass gasification, pyrolysis and torrefaction: practical design and theory. Academic Press, London

Baum M, Street P (1971) Predicting the combustion behaviour of coal particles. Combust Sci Technol 3(5):231-243

Chee CS (1987) The air gasification of wood chips in a commercial downdraft gasifier (Doctoral dissertation, Dissertação (Mestrado). Department of Chemical Engineering. Kansas State University, Manhattan

Chopra S, Jain A (2007) A review of fixed bed gasification systems for biomass. Agricultural Engineering International: the CIGR Ejournal. Invited Overview No. 5. Vol. IX

Dasappa S, Sridhar H, Sridhar G, Paul P, Mukunda H (2003) Biomass gasification-a substitute to fossil fuel for heat application. Biomass Bioenergy 25(6):637-649

Doherty W, Reynolds A, Kennedy D (2009) The effect of air preheating in a biomass CFB gasifier using ASPEN Plus simulation. Biomass Bioenergy 33(9):1158-1167

Fernando N, Narayana M (2016) A comprehensive two dimensional computational fluid dynamics model for an updraft biomass gasifier. Renew Energy 99:698-710

Hasler P, Nussbaumer T (1999) Gas cleaning for IC engine applications from fixed bed biomass gasification. Biomass Bioenergy 16(6):385-395
Hassanizadeh M, Gray WG (1980) General conservation equations for multi-phase systems: 3 . Constitutive theory for porous media flow. Adv Water Res 3(1):25-40

Higman C (2008) Gasification, combustion engineering issues for solid fuel systems. Elsevier, Amsterdam, pp 423-468

Jahirul MI, Rasul MG, Chowdhury AA, Ashwath N (2012) Biofuels production through biomass pyrolysis-a technological review. Energies 5(12):4952-5001

Jayathilake R, Rudra S (2017) Numerical and experimental investigation of Equivalence Ratio (ER) and feedstock particle size on birchwood gasification. Energies 10(8):1232

Kan T, Strezov V, Evans TJ (2016) Lignocellulosic biomass pyrolysis: a review of product properties and effects of pyrolysis parameters. Renew Sustain Energy Rev 57:1126-1140

Kerstein AR (1992) Linear-eddy modelling of turbulent transport. Part 7. Finite-rate chemistry and multi-stream mixing. J Fluid Mech 240:289-313

Klass DL (1998) Biomass for renewable energy, fuels, and chemicals. Academic Press, London

Kumar U, Paul MC (2019) CFD modelling of biomass gasification with a volatile break-up approach. Chem Eng Sci 195:413-422

Launder BE, Sharma B (1974) Application of the energy-dissipation model of turbulence to the calculation of flow near a spinning disc. Lett heat mass transf 1(2):131-137

Liu H, Elkamel A, Lohi A, Biglari M (2013) Computational fluid dynamics modeling of biomass gasification in circulating fluidized-bed reactor using the Eulerian-Eulerian approach. Ind Eng Chem Res 52(51):18162-18174

Lu D, Yoshikawa K, Ismail TM, El-Salam MA (2018) Assessment of the carbonized woody briquette gasification in an updraft fixed bed gasifier using the Euler-Euler model. Appl Energy 220:70-86

Mahinpey N, Gomez A (2016) Review of gasification fundamentals and new findings: reactors, feedstock, and kinetic studies. Chem Eng Sci 148:14-31

Meenaroch P, Kerdsuwan S, Laohalidanond K (2015) Development of kinetics models in each zone of a $10 \mathrm{~kg} / \mathrm{hr}$ downdraft gasifier using computational fluid dynamics. Energy Procedia 79:278-283

Murugan P, Sekhar SJ (2017) Species-transport CFD model for the gasification of rice husk (Oryza sativa) using downdraft gasifier. Comput Electron Agric 139:33-40

Pandey A, Larroche C, Gnansounou E, Khanal SK, Dussap C-G, Ricke S (2019) Biomass, biofuels, biochemicals: biofuels: alternative feedstocks and conversion processes for the production of liquid and gaseous biofuels. Academic Press, London

Pérez-Bayer JF, Barrera-Zapata R, Salazar-Jiménez CA (2016) Effect of Colombian coal rank and its feeding technology on substitute natural gas production by entrained gasification. Revista Facultad de Ingeniería 25(41):41-53

Rezaiyan J, Cheremisinoff NP (2005) Gasification technologies: a primer for engineers and scientists. CRC Press, Boca Raton

Richardson Y, Drobek M, Julbe A, Blin J, Pinta F (2015) Biomass gasification to produce syngas, recent advances in thermochemical conversion of biomass. Elsevier, Amsterdam, pp 213-250

Ruiz JA, Juárez M, Morales M, Muñoz P, Mendívil M (2013) Biomass gasification for electricity generation: review of current technology barriers. Renew Sustain Energy Rev 18:174-183

Saar G (1963) Estimation of heating value of Estonian oil shaleKukersite. Transactions of Tallinn Polytechnical Institute, Tallinn, pp 37-54

Savolainen K (2003) Co-firing of biomass in coal-fired utility boilers. Appl Energy 74(3-4):369-381

Senelwa KA (1997) Air gasification of woody biomass from short rotation forests: opportunities for small scale biomass-electricity 
systems: a thesis submitted in partial fulfilment of the requirements for the degree of Doctor of Philosophy in Agricultural Engineering at Massey University, New Zealand. Massey University

Sikarwar VS, Zhao M, Clough P, Yao J, Zhong X, Memon MZ, Shah N, Anthony EJ, Fennell PS (2016) An overview of advances in biomass gasification. Energy Environ Sci 9(10):2939-2977

Susastriawan A, Saptoadi H (2017) Small-scale downdraft gasifiers for biomass gasification: a review. Renew Sustain Energy Rev 76:989-1003
Warnecke R (2000) Gasification of biomass: comparison of fixed bed and fluidized bed gasifier. Biomass Bioenergy 18(6):489-497

Werther J, Saenger M, Hartge E-U, Ogada T, Siagi Z (2000) Combustion of agricultural residues. Prog Energy Combust Sci 26:1-27

Wu Y et al (2013) Two-dimensional computational fluid dynamics simulation of biomass gasification in a downdraft fixed-bed gasifier with highly preheated air and steam. Energy Fuels 27(6):3274-3282

Yucel O, Hastaoglu MA (2016) Kinetic modeling and simulation of throated downdraft gasifier. Fuel Process Technol 144:145-154 